\title{
The Effectiveness of Basal Shoot Mechanical Leaf Removal at the Onset of Bloom to Control Crop on cv. Sangiovese ( $V$. vinifera L.): Report on a Three-year Trial
}

\author{
C. Intrieri*, I. Filippetti, G. Allegro, G. Valentini, C. Pastore, E. Colucci \\ Department of Agricultural Sciences of the University of Bologna, Viale G. Fanin 46, 40068, Bologna (Italy)
}

Submitted for publication: July 2016

Accepted for publication: September 2016

Key words: Leaf removal, source-sink balance, fruit set, cluster compactness, labour requirement

\begin{abstract}
Vine basal shoot leaves are known to be the primary nutritional source for fruit set at the onset of bloom. The effectiveness of mechanical removal of this foliage at that date was tested from 2012 to 2014 to control the cropping of high-yielding cv. Sangiovese in a "Toscana rosso" TGI (Typical Geographic Indication) district in Tuscany, where the yield threshold is $16 \mathrm{t} / \mathrm{ha}$. A tractor-mounted leaf remover featuring sideby-side rotary suction and feed rollers was employed along a $50 \mathrm{~cm}$ basal area of cropping shoots at the beginning of bloom; control was the usual manual thinning of clusters carried out at véraison in the same vineyard. Mechanical leaf removal eliminated about $30 \%$ of leaf area and some shoots and inflorescences, thus reducing cropping potential and even resulting in a physiological effect, as the resulting clusters were composed of lower numbers of berries and were less compact and less susceptible to mould than the control. By harvest, the defoliated vines showed higher leaf area, most likely because leaf removal at the onset of bloom may have triggered compensatory new growth, and their grapes had a higher content of soluble solids than the thinned control. While both treatments kept the yield below the $16 \mathrm{t} / \mathrm{ha}$ threshold - leaf removal at an estimated $15.1 \mathrm{t} / \mathrm{ha}$ and manual cluster thinning at $15.6 \mathrm{t} / \mathrm{ha}$ - mechanical defoliation notably reduced yearly labour input: an estimated $4 \mathrm{~h} / \mathrm{ha}$ against the $38 \mathrm{~h} / \mathrm{ha}$ from thinning.
\end{abstract}

\section{INTRODUCTION}

Accounting for nearly $10 \%$ of Italy's wine grape acreage, Sangiovese is known to be one of the country's most economically important cultivars and is especially prominent in regions like Emilia-Romagna, Tuscany and Marches. Sangiovese is a productive cultivar that is marked by a very high bud fertility and provided with large and compact clusters, and it needs careful management to control productivity, especially in areas where quality and cropping must be maintained at levels consonant with the rules of Typical Geographic Indication (TGI) and/or Origin Control Denomination (OCD) areas. The most widespread approach employed to control Sangiovese yield in appellation districts is manual bunch thinning. Practised in a one-to two-week window over véraison, it requires an expenditure of 30 to 50 hours of labour per hectare. While the bunch thinning can reduce yield, it can also lead to greater compactness of the remaining clusters through greater berry growth, thereby increasing their susceptibility to Botrytis infection.

A more recent alternative approach is basal leaf removal of the shoots at bloom. Based on the functional relationship of nutrient availability and cropping process, the elimination of shoot leaves adjacent to the basal inflorescences limits the nutrient supply to flowers and, hence, both fruit set and cropping capacity are reduced (Coombe, 1959, 1962; May et al., 1969; Quinlan \& Weaver, 1970; Caspari \& Lang, 1996). The resulting clusters are smaller, looser and less susceptible to grey mould. Trials of manual defoliation of the first four to eight basal-shoot leaves in pre- or post-bloom of cvs. Barbera and Trebbiano Romagnolo grown in pots and in the field, and of potted cv. Sangiovese, have proven the viability of the practice (Poni et al., 2005, 2006). More recent trials of Sangiovese grown in experimental plots have compared manual removal of the first six basal leaves at pre- and full bloom to basal mechanical leaf-stripping with a suction unit at the same times (Intrieri et al., 2008). Even though mechanical as opposed to manual removal left more leaf area, this technique also reduced berry set and yield. A subsequent trial supported these findings, indicating that machine leaf-stripping at bloom can replace manual bunch thinning at véraison and even effectively control cropping (Filippetti et al., 2011).

However, most of these mechanical leaf-removal trials on Sangiovese have been conducted in experimental plots of restricted acreage. Our investigation therefore sought to determine the technique's practical, long-term viability on the same cultivar planted in the extensive acreage of a largescale commercial vineyard. 


\section{MATERIALS AND METHODS}

The trial was performed from 2012 to 2014 in a large commercial vineyard in Tuscany, Grosseto Province, where the cv. Sangiovese crop is restricted to a ceiling of 16 tons per hectare under TGI standards as "Toscana Rosso". The vineyard features mature, cordon-trained Sangiovese vines of clone VCR 6, grafted onto $420 \mathrm{~A}$ at a $2 \mathrm{~m}$ inter- by $0.8 \mathrm{~m}$ intra-row spacing, or about $5 \mathrm{~km} / \mathrm{ha}$ of rows and 6000 vines/ ha. Although the cordons were spur pruned to only four to six one-bud spurs per vine, the vineyard is very productive and its bunches have always been manually thinned at véraison to keep production to the 16 ton/ha limit.

The trial was set up in a completely randomised design in a plot of more than two hectares composed of 40 rows, each of about $300 \mathrm{~m}$ in length. The rows were randomly assigned to two treatments: "control", consisting of the usual manual cluster thinning at véraison, and "leaf removal", performed mechanically at the onset of bloom without subsequent cluster thinning. In each treatment, data were collected in 16 plots of seven vines for a combined 112 vines per treatment.

In the leaf removal treatment, the leaves were mechanically stripped at the onset of bloom on 201205-15, 2013-05-20 and 2014-05-13, when only a few flower buttons were open. A tractor-mounted leaf remover featuring bilateral rotary suction rollers was employed. The working parameters were set by prior testing: tractor speed was $1.5 \mathrm{~km} / \mathrm{h}$ (about 3.5 to $4 \mathrm{~h} / \mathrm{ha}$ ), and the rotation of the suction rollers was $5 \mathrm{~km} / \mathrm{h}$. The rollers were held above the permanent cordons so as to eliminate the first five to six basal leaves of the shoots. The preliminary test runs indicated that these settings were the most efficient for stripping, even if a few shoots and inflorescences, or parts thereof, were lost in the process

In the control vines, the bunches were customarily thinned manually every year at the onset of veraison. The normal management guidelines were followed so that any clearly late-ripening and mould-infected clusters, as well as those obviously susceptible to rot because of being grouped too closely together and of very compact berries, were removed.

Trial harvest dates were 2012-09-17, 2013-09-23 and 2014-09-14. Every year the collected data included:

- leaf-area estimation and counts of shoots and inflorescences per vine before and after leaf removal. Leaf area was estimated in pre- and post-stripping by multiplying shoot-count number per vine by average leaf area of sample shoots, including feathers, taken each time from extra vines and measured with an LI $3000 \mathrm{~A}$ (Li-Cor Bioscience, Lincoln, Nebraska, USA). The number of inflorescences per shoot was considered as potential yield capacity (fertility).

- labour hours required on control vines for manual cluster thinning at the onset of véraison (early July), and count of clusters removed;

- samples of 20 berries taken from each plot of both treatments, collected during ripening and analysed for juice soluble solid content using a temperature-compensating CR50 refractometer (Maselli Misure Spa, PR, Italy).

- at harvest, for both treatments, vine leaf area estimates and cropping measurements, including cluster number and weight, berry number per cluster and weight, cluster compactness and Botrytis infection. Leaf area was estimated with the same method reported in the first bullet point above; cluster compactness was assessed visually using the OIV 204 index (1-9 scale, OIV, 1993); and Botrytis incidence was estimated as \% of infected area per bunch.

- at harvest, for both treatments, samples of 20 berries from each plot of both treatments were collected for analyses of soluble solids (CR50 refractometer, Maselli Misure Spa, $\mathrm{PR}$, Italy), titratable acidity and $\mathrm{pH}$. Titratable acidity and $\mathrm{pH}$ were analysed using a Crison Compact Tritator (Crison, Barcelona, Spain) with $0.5 \mathrm{~N} \mathrm{NaOH}$ (Sigma-Aldrich, St. Louis, MO, USA).

All the collected data were analysed statistically using the SAS software package (SAS Institute, Cary, North Carolina, USA). Incidence values of Botrytis expressed as $\%$ of infected area per bunch were subjected to arcsin square root transformation before analysis. No significant year $\mathrm{x}$ treatment differences were found over the three trial years, and the data in the tables are expressed as means, which were separated by the SNK test (Gomez \& Gomez, 1984).

Data related to the soluble solid content of the juice recorded every year during ripening were maintained separated for each year, and the differences between treatments at each date of each year were statistically analysed by the SNK test.

\section{RESULTS}

The pre- and post-defoliation leaf areas are shown in Table 1. While no differences between treatments were found before leaf removal, the data show that stripping removed a third of leaf area per vine on average. Table 2 indicates that while shoot and inflorescence counts were similar between treatments before defoliation, the defoliation reduced the average shoot number by about $10 \%$ and the

TABLE 1

Leaf area per vine before and after leaf removal; average of 2012 to 2014.

\begin{tabular}{llllll}
\hline & \multicolumn{3}{c}{ Before leaf removal } & \multicolumn{2}{c}{ After leaf removal } \\
\cline { 2 - 6 } & & & \multicolumn{2}{c}{ Leaf area/vine } \\
\cline { 2 - 6 } Treatment & Leaf area/vine $\left(\mathrm{m}^{2}\right)$ & $\begin{array}{l}\text { Leaf area removed/ } \\
\text { vine }\left(\mathrm{m}^{2}\right)\end{array}$ & $\begin{array}{l}\text { Leaf area left/ } \\
\text { vine }\left(\mathrm{m}^{2}\right)\end{array}$ & Removed $(\%)$ & Left $(\%)$ \\
\hline Control & $1.634 \mathrm{a}$ & --- & $1.634 \mathrm{a}$ & --- & 100 \\
Leaf removal & $1.595 \mathrm{a}$ & 0.464 & $1.131 \mathrm{~b}$ & 29.1 & 70.9 \\
Year x treatment interaction & n.s. & --- & n.s. & -- & n.s. \\
\hline
\end{tabular}

Different letters by column indicate significant differences between treatments separated by the SNK test, $\mathrm{P}=0.05$. n.s., not significant 
visible inflorescence number by some $17 \%$, thus lowering the potential shoot fertility of defoliated vines. Table 3 shows that manual control cluster thinning at véraison removed an average of 2.7 bunches per vine and required 23 seconds of labour per plant, for an estimated $38.3 \mathrm{~h} / \mathrm{ha}$.

The data in Table 4 show that, at harvest, leaf area of the defoliated vines was greater than that of the control. The defoliated vines showed a yield very similar to the control thinned vines, and the estimated overall production per treatment was also similar. The ratio of leaf area to yield and juice soluble solids were greater in the defoliated compared to the control vines. No significant differences were found for $\mathrm{pH}$ and titratable acidity. Figs 1, 2 and 3 show that the soluble solid content every year was mostly higher in the defoliated than in the control berry from the end of véraison to harvest.

Table 5 shows the data for yield components. Defoliated vines ripened a greater number of cluster, but the control clusters were much heavier and composed of a higher number of berries with a higher compactness and were more affected by Botrytis than the former.

\section{DISCUSSION}

Since before defoliation, the vines in both treatments showed uniform profiles of leaf area and number of shoots and visible inflorescences when averaged over the trial years (Tables 1 and 2), provided a solid basis for gauging the effects of leaf removal and manual cluster thinning. The relatively slow tractor drive speed, coupled with the high rpm of the rotating stripper drums - a fine-tuning dictated by preliminary testing - efficiently reduced the basal vine leaf area by about 30\% (Table 1). Notable too is the fact that the unit's removal of a few shoots and inflorescences in the process (Table 2) did not compromise plant vitality and helped to elicit the intended reduction in cropping. This consideration is at odds with that of a previous trial using a rotating blade stripper, in which the same effects were viewed negatively and suggested better machine calibration to prevent them (Intrieri et al., 2008). In a very vigorous and high-yielding vineyard, mechanical leaf removal by an effective method, such as the one used in the present study, can thus be considered comparable to other management practices used for crop control, like hormone and growth-regulator treatments at bloom (Weaver, 1960; Szyjewicz et al., 1984) and the thinning of post-set berries and clusters by bow-rod shaker mechanical harvester units (Pool et al., 1988; 1993; Fendinger et al., 1996; Petrie \& Clingeleffer, 2006; Dokoozlian, 2013). Nevertheless, our data show that the decrease in the number of shoots and inflorescences due to a direct effect of the stripper only partially contributed to the decreased crop, since more

TABLE 2

Number of shoots and inflorescences per vine and related potential fertility before and after leaf removal; average of 2012 to 2014.

\begin{tabular}{lllllll}
\hline & \multicolumn{2}{c}{ Before leaf removal } & \multicolumn{2}{c}{ After leaf removal } \\
\cline { 2 - 7 } Treatment & $\begin{array}{l}\text { Shoot } \\
\text { (no./vine) }\end{array}$ & $\begin{array}{l}\text { Inflorescence } \\
\text { (no./vine) }\end{array}$ & $\begin{array}{l}\text { Potential fertility } \\
\text { (inflorescence/shoot) }\end{array}$ & $\begin{array}{l}\text { Shoot } \\
\text { (no./vine) }\end{array}$ & $\begin{array}{l}\text { Inflorescence } \\
\text { (no./vine) }\end{array}$ & $\begin{array}{l}\text { Potential fertility } \\
\text { (inflorescence/shoot) }\end{array}$ \\
\hline Control & $7.4 \mathrm{a}$ & $10.8 \mathrm{a}$ & $1.5 \mathrm{a}$ & $7.4 \mathrm{a}$ & $10.8 \mathrm{a}$ & $1.5 \mathrm{a}$ \\
Leaf removal & $7.4 \mathrm{a}$ & $10.9 \mathrm{a}$ & $1.5 \mathrm{a}$ & $6.7 \mathrm{~b}$ & $9.0 \mathrm{~b}$ & $1.3 \mathrm{~b}$ \\
Year x & n.s. & n.s. & n.s. & n.s. & n.s. & n.s. \\
treatment & & & & & & \\
interaction & & & & & & \\
\hline
\end{tabular}

Different letters by column indicate significant differences between treatments separated by the SNK test, $\mathrm{P}=0.05$. n.s., not significant.

TABLE 3

Number of clusters removed manually at véraison and related labour time; average of 2012 to 2014.

\begin{tabular}{llll}
\hline Treatment & Removed cluster (no./vine) & Actual labour time (second/vine) & Estimated labour time (hour/ha) \\
\hline Control & 2.7 & 23 & 38.3 \\
Leaf removal & --- & --- & --- \\
\hline
\end{tabular}

TABLE 4

Leaf area, yield per vine and main must biochemical compounds at harvest; average of 2012 to 2014.

\begin{tabular}{llllllll}
\hline Treatment & $\begin{array}{l}\text { Leaf area/ } \\
\text { vine }\left(\mathrm{m}^{2}\right)\end{array}$ & $\begin{array}{l}\text { Yield } \\
(\mathrm{kg} / \mathrm{vine})\end{array}$ & $\begin{array}{l}\text { Estimated } \\
\text { yield }(\mathrm{t} / \mathrm{ha})\end{array}$ & $\begin{array}{l}\text { Leaf area/ } \\
\text { crop }\left(\mathrm{m}^{2} / \mathrm{kg}\right)\end{array}$ & $\begin{array}{l}\text { Soluble solids } \\
\left({ }^{\circ} \text { Brix }\right)\end{array}$ & $\begin{array}{l}\text { Titratable } \\
\mathrm{pH}\end{array}$ & $\begin{array}{l}\mathrm{acidity} \\
(\mathrm{g} / \mathrm{L})\end{array}$ \\
\hline Control & $2.406 \mathrm{~b}$ & $2.60 \mathrm{a}$ & 15.6 & $0.92 \mathrm{~b}$ & $21.25 \mathrm{~b}$ & $3.60 \mathrm{a}$ & $5.8 \mathrm{a}$ \\
Leaf removal & $2.754 \mathrm{a}$ & $2.52 \mathrm{a}$ & 15.1 & $1.10 \mathrm{a}$ & $22.30 \mathrm{a}$ & $3.65 \mathrm{a}$ & $5.7 \mathrm{a}$ \\
Year x treatment & n.s. & n.s. & n.s. & n.s. & n.s. & n.s. & n.s.
\end{tabular}

interaction

Different letters by column indicate significant differences between treatments separated by the SNK test, $\mathrm{P}=0.05$. n.s., not significant. 


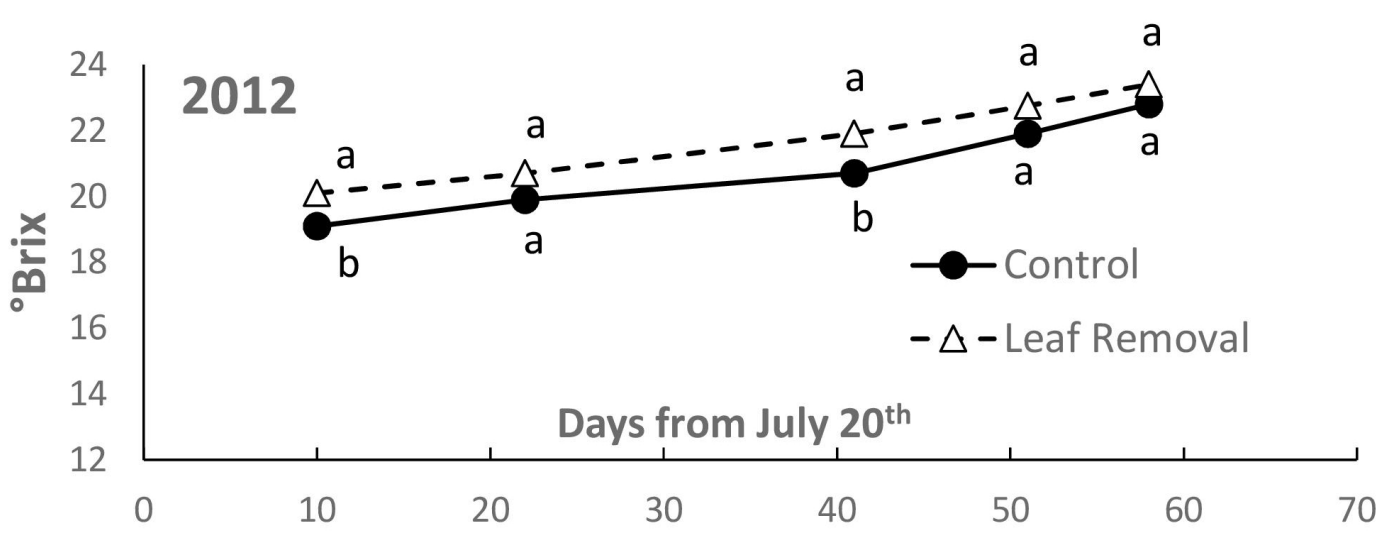

FIGURE 1

Soluble solids accumulation along the season. By date different letters indicate significant differences between treatments, separated by SNK test, $\mathrm{P}=0.05$.

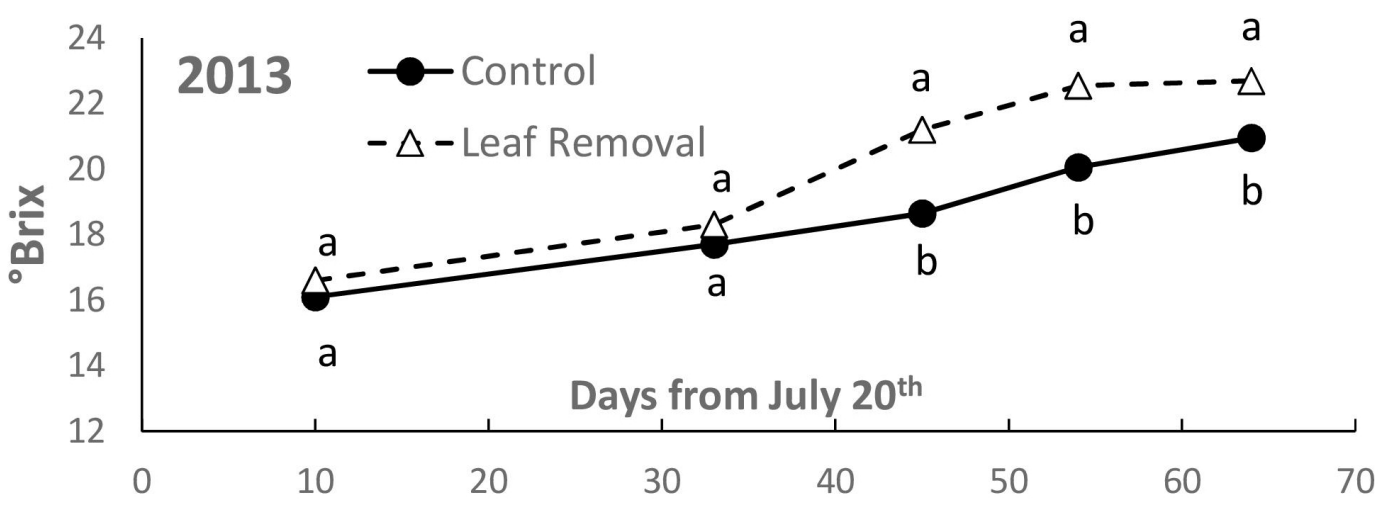

FIGURE 2

Soluble solids accumulation along the season. By date different letters indicate significant differences between treatments, separated by SNK test, $\mathrm{P}=0.05$

clusters were collected at harvest from the defoliated vines compared to the manual cluster-thinned control (Table 5). The most important point is that mechanical effects were followed by the 'downstream' physiological results of leaf removal. As a matter of fact, although the defoliated vines had more clusters than the thinned control, the yield of the two treatments was comparable (Table 4) as a result of the nearly $18 \%$ average bunch-weight reduction achieved by the former compared to the latter (Table 5). This result should be due mainly to the reduced fruit set of the defoliated vines, as the number of flowers that set during anthesis is physiologically linked to assimilating shoot-leaf area (Coombe, 1959; 1962; Caspari \& Lang, 1996; Poni et al., 2006; Intrieri et al., 2008). Cluster inspection confirmed that the bunches of defoliated vines had a lower number of berries at harvest (Table 5). Berries were also less tightly packed and, therefore, showed less Botrytis infection than the control (Table 5), as already reported by several authors (Lemut et al., 2015; Acimovic et al., 2016)

Overall, both leaf removal and cluster thinning were effective in controlling production, keeping it within the limit of $16 \mathrm{t} /$ ha set by the TGI standards for "Toscana rosso".
Noteworthy too is the fact that, although both practices achieved crop reduction (Table 4), manual cluster thinning did so in much more time than mechanical leaf stripping, i.e. in $38 \mathrm{~h} /$ ha (Table 3 ) against an estimated $4 \mathrm{~h}$ labour/ha.

As far as berry composition is concerned, the grapes of the defoliated vines at harvest showed a greater soluble solid content than that of the thinned control, despite a similar yield with the latter (Table 4). Several physiological factors appear to be at work here. We may speculate that the $15 \%$ higher leaf area of the defoliated vines at harvest (Table 4) was the result of a compensatory response that stimulated a surge in leaf area, presumably via new growth of laterals, as also reported elsewhere for the same cultivar (Poni et al., 2006; Pastore et al., 2013). This response elicited a leaf area-to-defoliated vine yield ratio that was greater than that of the control when calculated at harvest (Table 4). Yet the greater leaf area-to-defoliated vine yield ratio does not seem sufficient by itself to account for the higher ${ }^{\circ}$ Brix reading of the defoliated vis-à-vis control vine crop. Another contributing factor in this connection would appear to be the growth of post-fruit set young leaves, which replaced the stripped mature foliage, and hence increased vine 


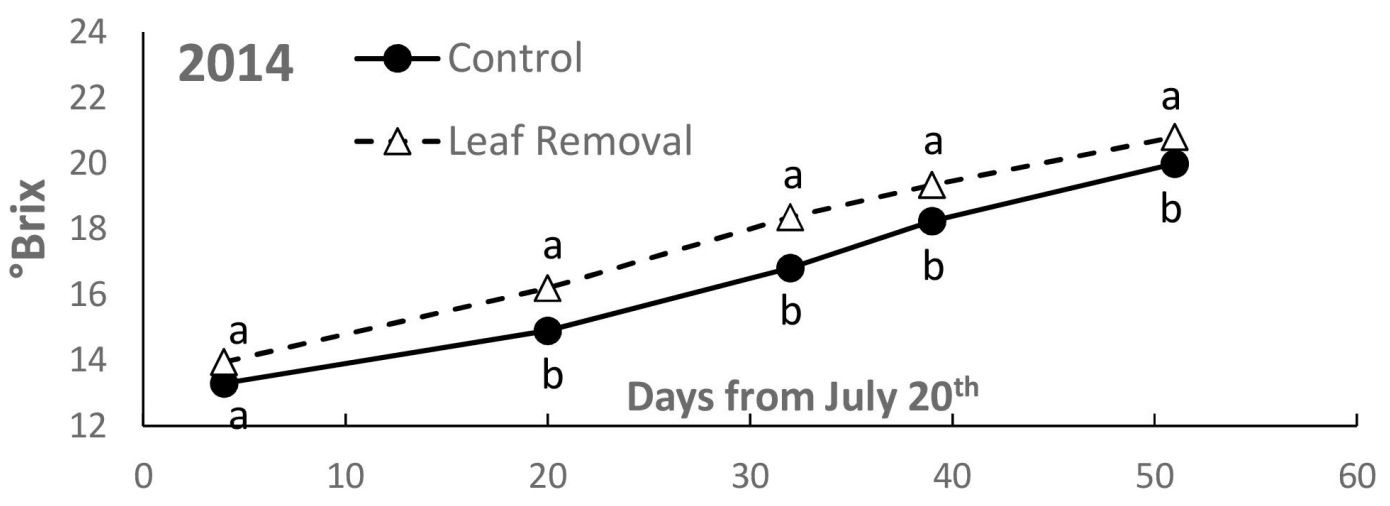

FIGURE 3

Soluble solids accumulation along the season. By date different letters indicate significant differences between treatments, separated by $\mathrm{SNK}$ test, $\mathrm{P}=0.05$.

TABLE 5

Number of clusters per vine, cluster and berry weight, cluster compactness and Botrytis incidence; average of 2012 to 2014.

\begin{tabular}{lllllll}
\hline Treatment & $\begin{array}{l}\text { Cluster } \\
(\text { no./vine) }\end{array}$ & $\begin{array}{l}\text { Cluster } \\
\text { weight }(\mathrm{g})\end{array}$ & $\begin{array}{l}\text { Berries } \\
(\text { no./cluster })\end{array}$ & $\begin{array}{l}\text { Berry } \\
\text { weight }(\mathrm{g})\end{array}$ & $\begin{array}{l}\text { Cluster compactness } \\
(\text { OIV 1-9) }\end{array}$ & $\begin{array}{l}\text { Botrytis incidence } \\
(\% \text { infected area/cluster })\end{array}$ \\
\hline Control & $10.0 \mathrm{~b}$ & $260 \mathrm{a}$ & $106 \mathrm{a}$ & $2.47 \mathrm{a}$ & $8.0 \mathrm{a}$ & $13.7 \mathrm{a}$ \\
Leaf removal & $11.6 \mathrm{a}$ & $217 \mathrm{~b}$ & $85 \mathrm{~b}$ & $2.51 \mathrm{a}$ & $6.7 \mathrm{~b}$ & $3.1 \mathrm{~b}$ \\
\hline
\end{tabular}

Different letters by column indicate significant differences between treatments separated by the SNK test, $\mathrm{P}=0.05$. n.s., not significant

photosynthetic efficiency at véraison, as also reported by others (Stoev et al., 1966; Kriedemann et al., 1970; Intrieri et al., 1992). This view seems to be supported by the fact that the berry samples tested periodically every year generally showed a greater amount of soluble solids after véraison in the stripped than in the control crop (Figs 1, 2 and 3). Leafarea regeneration also may have reduced excessive bunch light exposure and overheating during ripening, and may in turn have led to the fact that the former crop, compared to the latter, showed no significant variations in either tritatable acidity or $\mathrm{pH}$, in spite of the higher accumulation of soluble solids (Table 4).

That no significant year $\mathrm{x}$ treatment interaction was found over the trial years is also notable. It shows that the repeated effects of both treatments from year to year did not disrupt vine performance. This is a particularly important finding for leaf removal. The reason is that, although it prematurely eliminated part of the functional leaves at the base of shoots, leaf removal did not result in significant differences from the control vines with regard to the number of inflorescences per shoot recorded every year before the treatment (Table 2). As reported by Sanchez and Dokoozlian (2005) and by Intrieri et al. (2008), the potentially negative effect of early leaf removal during the initial period of flower bud differentiation may be offset by the improved microclimate light penetration in the basal shoot zone, where buds from the previous year assure proper cropping of permanent cordon-trained vines.

\section{CONCLUSIONS}

Our findings indicate that mechanical removal of vine basal shoot leaves at the onset of bloom is a viable practice in managing the economy and crop of vineyards that must comply with guidelines for quality and yield standards. While mechanical removal can readily replace manual cluster thinning even in mid-sized vineyards, which usually have such a unit, machine leaf removal is a useful tool especially for larger vineyards. Since the latter often have more than one stripping machine, they are used sparingly throughout a given season, hence defoliation at bloom extends their usefulness and notably cuts the costs needed to control yield.

It bears reiterating that, when necessary, vineyards working with very fertile cultivars in TGI or OCD areas must expend a notable amount of labour for manual bunch thinning, which should also be carried out over the narrow véraison window. If done earlier, it in part could offset the intended effects on yield control, as the remaining clusters will become heavier because of the increase in berry volume and weight, thereby also increasing their susceptibility to Botrytis infection. If done later, the resulting crop reduction may not be matched by an improvement in grape quality.

While mechanical leaf removal also should be conducted in a relatively short time frame, it is fast and gives growers a window of flexibility, since trials show that they have one to two weeks from pre-bloom to the end of anthesis to set their timetable (Intrieri et al., 2008). Moreover, early leaf removal controls not only yield by curtailing flower nutrient uptake and reducing fruit set, but modifies cluster morphology by reducing berry compactness and making the berries less susceptible to fungi attacks. 


\section{LITERATURE CITED}

Acimovic, D., Tozzini, L., Green, A., Sivilotti, P. \& Sabbatini, P. 2016. Identification of a defoliation severity threshold for changing fruitset, bunch morphology and fruit composition in Pinot Noir. Aust. J. Grape Wine Res. 22(3), 399-408.

Caspari, H.V. \& Lang, A., 1996. Carbohydrate supply limits fruit-set in commercial Sauvignon blanc grapevines. Proc. $4^{\text {th }}$ Int. Symp. on Cool Climate Enology and Viticulture, 16-20 July, Rochester NY, USA. pp. II 9- II 13.

Coombe, B.G., 1959. Fruit set development in seeded grape varieties as affected by defoliation, topping, girdling and other treatments. Am. J. Enol. Vitic. 10, 85-100.

Coombe, B.G., 1962. The effect of removing leaves, flowers and shoot tips on fruit-set in Vitis vinifera L. J. of Hort. Sci. 37, 1-15.

Dokoozlian, N., 2013. Evolution of mechanized vineyard production system in California. Proc. First Int. Workshop on Vineyard Mechanization and Grape and Wine Quality, 27-29 June, 2012, Piacenza, Italy. Acta Hortic. $978,265-278$

Fendinger, A.G., Pool, R.M., Dunst, R.M. \& Smith, R., 1996. Effect of mechanical thinning of minimally pruned "Concord" grapevines on fruit composition. Proc. $4^{\text {th }}$ Int. Symp. Cool Climate Viticulture and Enology, Rochester, New York, USA. 4, 13-17.

Filippetti, I., Allegro, G., Valentini, G., Pastore, C., Poni, S. \& Intrieri, C., 2011. Effects of mechanical pre-bloom defoliation on cordon de Royat Sangiovese (Vitis vinifera L.) vines. J. Int. Sci. Vigne Vin, 45(1), 19-25.

Gomez, K.A. \& Gomez, A.A., 1984. Statistical procedure for agricultural research. Wiley and Sons, Singapore.

Intrieri, C., Filippetti, I., Allegro, G., Centinari, M. \& Poni, S., 2008. Early defoliation (hand vs mechanical) for improved crop control and grape composition in Sangiovese (Vitis vinifera L.). Aust. J. Grape Wine Res. 14, 25-32.

Intrieri, C., Poni, O., Silvestroni, I. \& Filippetti, I., 1992. Leaf age, leaf position and photosynthesis in potted grapevines. Adv. Hort. Sci. 6, 23-27.

Kriedemann, P.E., Kliewer, W.M. \& Harris, J.M., 1970. Leaf age and photosynthesis in Vitis vinifera L. Vitis 9, 98-104.

Lemut, M.S., Sivilotti P., Butinari L., Laganis J. \& Vrhovsek., 2015. Preflowering leaf removal alters grape microbial population and offers good potential for a more sustainable and cost-effective management of a Pinot Noir vineyard. Aust. J. Grape Wine Res. 21, 439-450.
May, P., Shaulis, N.J. \& Antcliff, A.J., 1969. The effect of controlled defoliation in the Sultana vines. Am. J. Enol. Vitic. 20, 237-250.

OIV, 1993. Code des caractères descriptifs des varietès et éspèces de Vitis. OIV, Paris.

Pastore, C., Zenoni, S., Fasoli, M., Pezzotti, M., Tornielli, G.B. \& Filippetti, I., 2013. Selective defoliation affects plant growth, fruit transcriptional ripening program and flavonoid metabolism in grapevine. Plant Biol. 13(30), $1-16$.

Petrie, P.R. \& Clingeleffer, P., 2006. Crop thinning (hand vs. mechanical), grape maturity and anthocyanins concentration: Outcomes from irrigated Cabernet Sauvignon (Vitis vinifera L.) in a warm climate. Aust. J. Grape Wine Res. 45, 123-132.

Poni, S., Bernizzoni, F., Briola, G. \& Cenni, A., 2005. Effects of early leaf removal on cluster morphology, shoot efficiency and grape quality in two Vitis vinifera cultivars. Acta Hortic. 689, 217-225.

Poni, S., Casalini, L., Bernizzoni, F., Civardi, S. \& Intrieri, C., 2006. Effects of early defoliation on shoot photosynthesis, yield components and grape quality. Am. J. Enol. Vitic. 4, 397-407.

Pool, R.M., Crowe, D.C. \& Dunster, R.E., 1988. The use of combined mechanical or minimal pruning and mechanical thinning in New York vineyard production system. Proc. Sem. Mechanical Pruning of Vineyards, Villanova di Motta di Livenza, Treviso (Italy). pp. $39-43$.

Pool, R.M., Dunst, R.E., Crowe, D.C., Hubbart, H. \& Howard, G., 1993. Predicting and controlling crop of machine or minimal pruned grapevines. In: Pool, R.M. (ed.). Proc. $2^{\text {nd }}$ N.J. Shaulis Grape Symp., Fredonia State University, Fredonia, New York. pp. $31-45$.

Quinlan, J.D. \& Weaver, J.R., 1970. Modification of pattern of the photosynthate movement within and between shoots of Vitis vinifera L. Plant Phys. 46, 527-530.

Sanchez, L.A. \& Dokoozlian, N.K., 2005. Bud microclimate and fruitfulness in Vitis vinifera L. Am. J. Enol. Vitic. 56, 319-329.

Stoev, K., Dobreva, S.S. \& Zeynalov, Y., 1966. On the photosynthetic activity of vines leaves in different metameric positions. Hort. Vitic. Sci., $3(4), 501-513$.

Szyjewicz, E., Rosner, N. \& Kliewer, W.M., 1984. Ethepon (2-chloroetyl phosphonic acid, CEPA) in viticulture. A review. Am. J. Enol. Vitic. 35, 117-123.

Weaver, R.J. 1960. Toxicity of gibberellin to seedless and seeded varieties of Vitis vinifera. Nature 187, 1135-1136. 